\title{
Author Correction: Analytic model for the complex effective index of the leaky modes of tube-type anti- resonant hollow core fibers
}

\section{Matthias Zeisberger ${ }^{1} \&$ Markus A. Schmidt ${ }^{1,2,3}$}

Correction to: Scientific Reports https://doi.org/10.1038/s41598-017-12234-5, published online 18 September 2017

This Article contains errors within Figure 7, in which certain curves are distorted. The correct Figure 7 appears below as Figure 1:

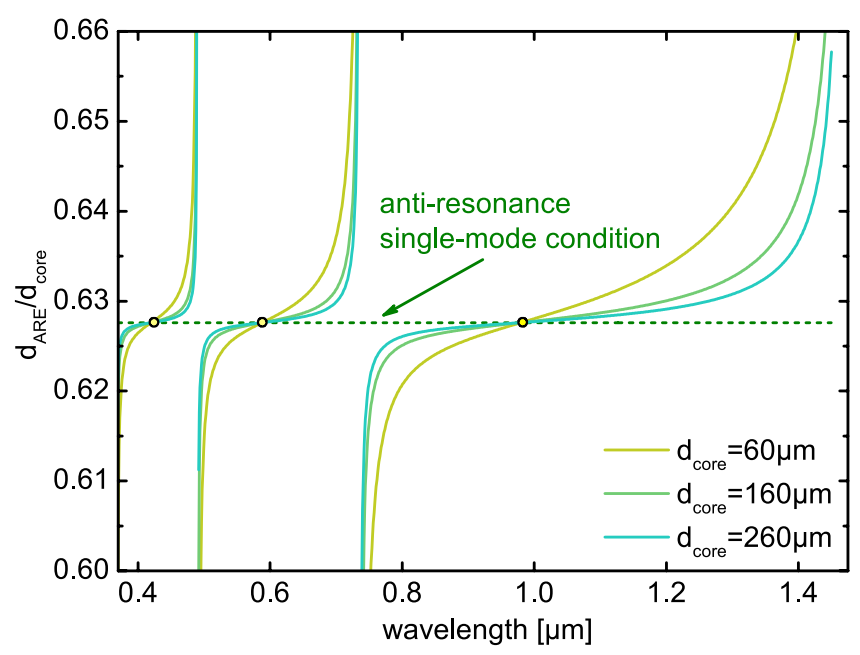

Figure 1.

(i) Open Access This article is licensed under a Creative Commons Attribution 4.0 International License, which permits use, sharing, adaptation, distribution and reproduction in any medium or format, as long as you give appropriate credit to the original author(s) and the source, provide a link to the Creative Commons license, and indicate if changes were made. The images or other third party material in this article are included in the article's Creative Commons license, unless indicated otherwise in a credit line to the material. If material is not included in the article's Creative Commons license and your intended use is not permitted by statutory regulation or exceeds the permitted use, you will need to obtain permission directly from the copyright holder. To view a copy of this license, visit http://creativecommons.org/licenses/by/4.0/.

(C) The Author(s) 2018

${ }^{1}$ Leibniz Institute of Photonic Technology, Albert-Einstein-Str. 9, 07745, Jena, Germany. ${ }^{2}$ Otto Schott Institute of Materials Research (OSIM), Friedrich Schiller University of Jena, Fraunhoferstr. 6, 07743, Jena, Germany. ${ }^{3}$ Abbe Center of Photonics and Faculty of Physics, Friedrich Schiller University Jena, Max-Wien-Platz 1, Jena, 07743, Germany. Correspondence and requests for materials should be addressed to M.Z. (email: matthias.zeisberger@leibniz-ipht.de) 